\title{
Assertion and Assurance: Some Empirical Evidence
}

\author{
JOHN TURRI
}

University of Waterloo

I report three experiments relevant to evaluating Krista Lawlor's theory of assurance, respond to her criticism of the knowledge account of assertion, and propose an alternative theory of assurance.

\section{Introduction}

Krista Lawlor's Assurance is a rich and stimulating work. Lawlor argues that assurance is "a distinctive speech act," that assurance "is not the speech act of assertion," and that assurance has a special relationship to claiming that one has knowledge (Lawlor 2013, quotes from pp. 9, 3; unless otherwise noted, all parenthetical page references are to this work). Because she theorizes about the nature and function of some familiar aspects of ordinary language, her theory is answerable to empirical facts about actual usage. Lawlor admirably acknowledges this constraint. She bases her theory on "facts about usage" (p. 22), which constitute "data that any account" in this area "must ... respect and explain" (p. 80).

I do three things in this paper. I report three simple experiments that test whether Lawlor's theory is headed in the right direction. I evaluate what Lawlor describes as "compelling criticisms of the knowledge account of assertion." And I suggest an alternative theory of assurance.

\section{Recognizing a Potential Change of Mind: Experiment 1}

Lawlor looks to the "normative dimensions of assurance" to distinguish it from assertion (pp. 11-15). Assertion and assurance, Lawlor hypothesizes, differ in how one represents oneself when performing them. When one asserts that a proposition is true, "it is recognized that there may be further 
evidence or circumstances that change [one's] opinion" on the matter. By contrast, when one assures that a proposition is true, it is not recognized that further evidence or circumstances might change one's opinion. Instead, one represents oneself as having "conclusive reasons" that show any further counterevidence to be misleading. If Lawlor's hypothesis is true, then it should have detectable consequences for how people think conversational partners should interpret one another.

To test this hypothesized difference, I conducted a simple experiment with eighty participants. ${ }^{1}$ Participants were randomly assigned to one of two conditions, Assertion and Assurance. Each participant read a single story about Jeff and Sally. The only difference between the two stories is that in the Assertion story Jeff makes an unadorned assertion using a simple declarative sentence, whereas in the Assurance story he explicitly adds "I assure you." Here is the text:

Jeff and Sally are driving to their appointment. They left right on schedule, but they had to take a detour because of some road construction. Sally asks if they will arrive by five o'clock. Jeff replies, "We will arrive by five o'clock[, I assure you]."

After reading the story, participants rated their agreement with the key test statement:

1. Sally should recognize that, depending on how things go, Jeff might change his mind about when they'll arrive.

Responses were collected on a 6-point Likert scale anchored with "Strongly Disagree" (-3), "Disagree" (-2), "Somewhat Disagree" (-1), "Somewhat Agree" (1), "Agree" (2), and "Strongly Agree" (3), appearing left-to-right across the participant's screen. (Participants never saw the numerical labels, only the qualitative anchors. The same is true in all experiments below.)

The first critical question is whether participants in the Assurance condition were more likely to disagree with the test statement. If they were, then it supports Lawlor's hypothesis. But if they were not, then it undermines Lawlor's hypothesis. They were not. Mean response in the Assurance condition $(\mathrm{M}=0.70, \mathrm{SD}=1.79)$ did not differ from mean response in the Assertion condition $(\mathrm{M}=0.93, \mathrm{SD}=1.69) .{ }^{2}$ A second critical question is

Aged 18-67, mean age $=33 ; 35$ female; $92 \%$ native English speakers. Participants were recruited and tested online (using Amazon Mechanical Turk and Qualtrics) and compensated $\$ 0.35$ for approximately 2 minutes of their time. Repeat participation was prevented. For all subsequent experiments reported here, I recruited and compensated all participants similarly.

2 Independent samples t-test, $\mathrm{t}(78)=0.58, \mathrm{p}=.564$. All reported tests are two-tailed. 
whether participants in the Assurance condition tended to disagree with the test statement. If Lawlor's hypothesis is true, then we should expect them to disagree. But this is not what we observe. Instead participants in each condition tended to agree. ${ }^{3}$ The mode response was "Agree" in both Assertion (40\%) and Assurance (45\%) conditions.

To ensure that the manipulation was effective, I included three additional probes. Each appeared on a new screen after the key test statement. (Participants could not go back and change answers, and the story remained at the top of the screen throughout.) The second and third probes asked participants to rate their agreement, on the same 6-point scale as above, with the following statements:

2. Jeff assured Sally that they will arrive by five o'clock.

3. Jeff told Sally that they will arrive by five o'clock.

As expected, mean agreement with the second probe was higher in the Assurance condition $(\mathrm{M}=2.48, \mathrm{SD}=0.88)$ than in the Assertion condition $(\mathrm{M}=2.08, \mathrm{SD}=0.86){ }^{4}$ Mean agreement with the third probe did not differ between the Assurance $(\mathrm{M}=2.43, \mathrm{SD}=0.98)$ and Assertion conditions $(\mathrm{M}=2.43, \mathrm{SD}=1.15) .^{5}$ For the final probe, participants were asked, "Which better describes what Jeff did?" and then presented with an open sentence.

4. He Sally that they will arrive by by five o'clock. (told/ assured)

Responses options for the fourth probe were rotated randomly. As expected, significantly more participants in the Assurance condition (93\%) than in the Assertion condition (50\%) answered "assured." 6 Participants in the Assurance condition chose this answer at rates far exceeding chance, ${ }^{7}$ whereas participants in the Assertion condition were evenly split. ${ }^{8}$ These

3 One sample t-tests, test proportion $=0$. Assertion, $\mathrm{t}(39)=3.47, \mathrm{p}=.001, \mathrm{MD}=0.93$, $95 \% \mathrm{CI}=0.39$ to $1.46, \mathrm{~d}=0.55$. Assurance, $\mathrm{t}(39)=2.48, \mathrm{p}=.018, \mathrm{MD}=0.70,95 \%$ $\mathrm{CI}=0.13$ to $1.27, \mathrm{~d}=0.39$.

4 Independent samples t-test, $\mathrm{t}(78)=2.06, \mathrm{p}=.043, \mathrm{MD}=0.40,95 \% \mathrm{CI}=0.01$ to 0.79 , $\mathrm{d}=0.47$.

$5 \quad$ Independent samples t-test, $\mathrm{t}(78)=0.00, \mathrm{p}=1$.

6 Chi-square test for independence, $\chi 2(\mathrm{n}=80$, df $=1)=17.64, \mathrm{p}<.001$, Cramer's $\mathrm{V}=$ 47 .

$7 \quad$ Chi-square test for goodness of fit, $\chi 2(\mathrm{n}=40, \mathrm{df}=1)=28.90, \mathrm{p}<.001$.

8 Chi-square test for goodness of fit, $\chi^{2}(\mathrm{n}=40, \mathrm{df}=1)=0.00, \mathrm{p}=1$. Within the Assert condition, response to the final probe did not predict response to the key test question, linear regression, Beta $=.075, \mathrm{p}=.645$. 
results show that the manipulation was effective and participants are sensitive to the difference between assuring and (merely) asserting.

Lawlor hypothesized that we represent ourselves as having very different evidence when we make an assurance than when we make a mere assertion. This is supposed to be reflected in what we "recognize" for assurances and assertions. More specifically, we recognize that an asserter might subsequently change his mind in light of new developments, whereas we do not recognize that an assurer might do this. The results from the present experiment suggest that this is not reflected in how we think people should interpret one another. However, Lawlor considers this "just a first rough pass in our effort to understand" what distinguishes assurance from assertion. The next section looks at another hypothesis she offers.

\section{Natural Conjunctions: Experiment 2}

Lawlor hypothesizes that "the function of assurance is to give hearers exclusionary reasons," whereas this is not the function of assertion (pp. 15-22). An exclusionary reason to believe a proposition allows one to "disregard other reasons one might have against" the proposition, which enables us to properly "stop weighing reasons and get on about our business" (pp. 18, 20). Lawlor argues that "usage supports" this hypothesis. In particular, she claims, "It is natural to say 'p, but see for yourself'; it's not so natural to say "I know p, but see for yourself"' (p. 19). (She assumes that saying "I know" a proposition counts as an assurance that the proposition is true.)

To test the claim about what is natural, I conducted a simple experiment with eighty-two new participants. ${ }^{9}$ Participants were randomly assigned to one of two conditions, Assertion and Assurance. Each participant read a single story about Jeff and Sally, this time discussing what to eat for dinner. The only difference between the two stories is that in the Assertion story Sally makes an unadorned assertion using a simple declarative sentence, whereas in the Assurance story she adds "I know." In each story Sally ends by adding the independent clause "but go ahead and see for yourself." Here is the text:

Jeff and Sally are deciding what to eat for dinner. Sally looks in the refrigerator and notices that they have leftovers. Jeff asks whether the leftovers have been sitting around for too long. Sally answers, "[They are/I know they're] fine, but go ahead and see for yourself."

Aged 18-59, mean age $=29 ; 24$ female; $95 \%$ native English speakers. 
Participants then responded to the key test statement:

1. In terms of how people ordinarily talk, Sally's answer at the end was

Responses were collected on a 6-point Likert scale anchored with "very unnatural" (-3), "unnatural" (-2), "somewhat unnatural" (-1), "somewhat natural" (1), "natural" (2), and "very natural" (3), left-to-right across the participant's screen.

The critical question is whether participants in the Assurance condition were more likely to view Sally's answer as unnatural. If they were, then it supports Lawlor's hypothesis. But if they were not, then it undermines Lawlor's hypothesis. They were not. Mean response in the Assurance condition $(\mathrm{M}=1.10, \mathrm{SD}=1.43)$ did not differ from mean response in the Assertion condition $(\mathrm{M}=1.00, \mathrm{SD}=1.58)$. Participants in the Assurance condition tended to rate the statement as natural, ${ }^{10}$ and no less natural than in the Assertion condition. ${ }^{11}$ The mode response was "natural" in both Assertion (44\%) and Assurance (44\%) conditions.

As a check on the robustness of the findings from Experiment 1, I included a second probe on a new screen.

2. Jeff should recognize that, depending on how things go, Sally might change her mind about whether the leftovers are fine.

Responses were collected on the same 6-point Likert scale used for the analogous question in Experiment 1. The results replicated the earlier findings. There was no difference in mean agreement between the two conditions, ${ }^{12}$ and overall the trend was for people to agree that Jeff should recognize that Sally might change her mind depending on things go. ${ }^{13}$

Lawlor hypothesized that assurance, but not assertion, functions to provide others with reasons that allow them to discount potential counterevidence, end deliberation and act. She supported this hypothesis by claiming that it reflects ordinary usage. In particular, she said that although it is natural to follow up an assertion with "but see for yourself," it is not natural to follow up an assurance that way. The results from the present experiment

\footnotetext{
10 One sample t-test, test proportion $=0, \mathrm{t}(40)=4.92, \mathrm{p}<.001, \mathrm{MD}=1.10,95 \% \mathrm{CI}=$ 0.65 to $1.55, \mathrm{~d}=0.77$.

11 Independent samples t-test, $\mathrm{t}(80)=0.58, \mathrm{p}=.770$. Assertion: $\mathrm{M}=0.49, \mathrm{SD}=1.79$. Assurance, $\mathrm{M}=0.12, \mathrm{SD}=1.52$. Independent samples t-test, $\mathrm{t}(80)=1.0, \mathrm{p}=.322$. 
suggest that this is false. Adding "but see for yourself" is natural for both assertion and assurance.

\section{Eavesdropping and Blame: Experiment 3}

Thus far we've evaluated two different hypotheses for distinguishing assurance from assertion. Neither seems to work. After presenting the hypotheses, Lawlor proposes to focus more directly on understanding "the normative demands of assurance giving" (p. 21). Again she appeals to "facts about usage" - and in particular "one revealing fact about usage" - to advance her inquiry. The alleged fact is this: if one person offers assurance to a second party, then a third party eavesdropping on the exchange can treat the first person "as a guarantor" and "blame her if she is in error." Lawlor calls this a "datum" that shows us "something important about the extent of one's commitment in giving an assurance." In particular, she thinks it shows that someone who offers an assurance is thereby accountable to "all hearers, actual or potential" (p. 22).

To test this whether this is a fact, I again conducted a simple experiment with eighty-three new participants. ${ }^{14}$ Participants were randomly assigned to one of two conditions, Partner and Eavesdropper. Each participant read a single story about Jeff and Sally, this time discussing investment in biotechnology. In each story Sally assures Jeff that a certain firm is the best investment, and an eavesdropper, Penelope, overhears this. The only difference between the two stories is that in the Partner story Jeff invests in the firm, whereas in the Eavesdropper story Penelope invests in the firm. In each story the investment is a disaster. Here is the text:

Jeff and Sally are having a private conversation about which biotechnology firm is the best investment over the next year. Sally says to Jeff, "NanoGenes is the best investment, I assure you." It turns out that another person, Penelope, is in the next room eavesdropping on their conversation. ${ }^{15}$

Based on what Sally said, [Jeff/Penelope] invested in NanoGenes. It was a disaster and [Jeff/Penelope] lost all the money [he/she] invested.

Participants then responded to the key test statement:

1. [Jeff/Penelope] blame Sally for being wrong about NanoGenes.

Responses were collected on a 6-point Likert scale anchored with "definitely cannot" (-3), "cannot" (-2), "probably cannot” (-1), "probably can” (1),

Aged 19-66, mean age $=35 ; 44$ female; $92 \%$ native English speakers.

15 Indicates paragraph break on the participant's screen. 
"can" (2), and "definitely can" (3), left-to-right across the participant's screen. Participants then went to a new screen and answered a manipulation check: "Sally assured _ that NanoGenes was the best investment" (Jeff/Penelope). The manipulation was extremely effective, with $99 \%$ of participants answering that Sally assured Jeff.

The critical question is whether participants in the Eavesdropper condition answered that Penelope can blame Sally for being wrong about the company. If they did, then it supports Lawlor's "datum" about assurance. But if they did not, then it undermines Lawlor's datum. They did not. Participants in the Eavesdropper condition overwhelmingly answered that Penelope cannot blame Sally $(\mathrm{M}=-1.73, \mathrm{SD}=1.72) .{ }^{16}$ Mean response in the Partner condition was very different $(\mathrm{M}=0.05, \mathrm{SD}=1.85) .{ }^{17}$ The mode response was "probably can" in the Partner condition and "definitely cannot" in the Eavesdropper condition. Only $15 \%$ of participants in the Eavesdropper condition answered "probably can," "can" or "definitely can," compared to $60 \%$ of participants who chose one of those answers in the Partner condition.

Lawlor claimed it is a datum, reflected in ordinary usage, that offering assurance renders one liable to blame from "all hearers, actual or potential," including third parties who happen to overhear the assurance. The results from the present experiment strongly suggest that it does not reflect ordinary usage. Instead, people strongly judged that a third party was not entitled to blame someone overheard making an assurance.

\section{Knowledge, Assertion and Blameless Rule-Breaking}

Lawlor anticipates a theoretical argument against "the very idea of a distinctive speech act of assurance" (p. 48). The argument presupposes that you should make an assertion only if you know it's true. Lawlor correctly points out that the argument fails and that there is no tension between the knowledge account of assertion and postulating a speech act of assurance. But she also goes on to argue that the knowledge account of assertion faces "compelling criticisms" (p. 11).

The initial advertisement was for "compelling criticisms." But it turns out that there is only a single criticism (pp. 50-52). Lawlor begins by noting that "we find many instances where speakers violate the knowledge rule, and no one blames them." The most common examples of this are false assertions that express beliefs supported by good but misleading evidence. We do not need to speculate about how to understand these

\footnotetext{
16 One same t-test, test proportion $=0, \mathrm{t}(40)=-6.46, \mathrm{p}<.001, \mathrm{MD}=-1.73,95 \% \mathrm{CI}=$ -2.27 to $-1.19, \mathrm{~d}=1.01$. 
examples because it has been empirically demonstrated that they are instances of blamelessly breaking the rule of assertion (Turri 2013; Turri \& Blouw 2014). So what is the problem? Lawlor continues,

In the face of possible widespread violation, we need to know (i) in what sense the norm in fact applies, if it can be violated apparently without anyone noting as much and (ii) what are the consequences of its obtaining, again, if its violations are so routinely allowed? (p. 50)

Lacking answers to these questions, Lawlor writes, the defense of the knowledge account is "unprincipled."

After raising these questions, Lawlor reviews a possible analogy with the speech act of commanding, which a proponent of the knowledge account might try to utilize. She argues that the analogy fails, but she does not consider other responses to the questions. ${ }^{18}$ Nevertheless, a simple, direct and effective response is readily available: the questions fail to identify a problem for the knowledge account of assertion. First, no evidence is offered that the knowledge rule for assertion is broken any more often than rules for other activities. Second, no evidence is offered that blameless transgression of the knowledge rule is any more "routine" than it is for other rules. Third, for any given rule, it is possible for there to be widespread blameless violation, so the possibility of widespread blameless violation of the knowledge rule is utterly unexceptional.

\section{Conclusion}

My three initial attempts to find tangible evidence in favor of Lawlor's theory of assurance failed. Of course we should not draw drastic conclusions from this, because further investigation might yield more encouraging results. Nevertheless, in light of the current findings, it's likely that at least some aspects of the theory should be adjusted.

In conclusion, I would like to suggest an alternative theory of the speech act of assurance: assuring is simply a mode of asserting, distinguished by its relation to other aspects of discourse. On this view, assuring is similar to conceding or admitting. Saying "The proof is invalid" is an assertion, and so is saying "The proof is invalid, I admit." However, a plain assertion and an admission relate differently to other aspects of the discourse in which they occur. Under almost any circumstance, as an opening move in a

18 For the record, the argument that the analogy fails did not persuade me. For it overlooks a natural "ground-level telling-that" analogous to the "ground-level telling-to," which is supposedly the key missing ingredient that causes the analogy with commanding to fail. The natural analog is, quite simply, telling-to-believe. It's just a special case of a more general telling-to-do. 
conversation, admitting that the proof is invalid would be quite silly. But asserting it would not be silly as an opening move. Similarly, saying "The book is in my bag" is an assertion, and so is saying "The book is in my bag, I admit." But the admission becomes sensible only in a context where something like an accusation or suspicion has already been directed against you. Finally, on the proposed view, saying "We will be there by five o'clock" is an assertion, and so is saying "We will be there by five o'clock, I assure you." But the two relate differently to other aspects of the discourse. Reassuring becomes sensible only if one's audience is apt to be worried or anxious about things turning out a certain way. If my hypothesis is correct, then it could explain the results discussed above. In particular, it could explain why people consistently responded similarly to assertions and assurances. ${ }^{19}$

\section{References}

Lawlor, K. (2013). Assurance: An Austinian view of knowledge and knowledge claims. Oxford: Oxford University Press.

Turri, J. (2013). The test of truth: An experimental investigation of the norm of assertion. Cognition, 129(2), 279-291. doi:10.1016/j.cognition. 2013.06.012

, and Blouw, P. (2014). Excuse validation: A study in rule-breaking. Philosophical Studies. doi:10.1007/s11098-014-0322-Z supported by the Social Sciences and Humanities Research Council of Canada and an Early Researcher Award from the Ontario Ministry of Economic Development and Innovation. 